\section{Parirás sin dolor: poder médico, género y política en las nuevas formas de atención del parto en la Argentina (1960-1980)}

\section{Without pain you will bring forth children: medical power, gender, and politics in new forms of assisted childbirth in Argentina (1960-1980)}

\section{Karina Felitti}

Pesquisadora do Conicet no Instituto Interdisciplinario de Estudios de Género da Facultad de Filosofía y Letras/Universidad de Buenos Aires. Puán, 480/6ㅇ piso/417/460 C1406CQJ - Buenos Aires - Argentina

kfelitti@fibertel.com.ar

Recebido para publicação em março de 2011. Aprovado para publicação em agosto de 2011.
FELITTI, Karina. Parirás sin dolor: poder médico, género y política en las nuevas formas de atención del parto en la Argentina (1960-1980). História, Ciências, Saúde - Manguinhos, Rio de Janeiro, v.18, supl.1, dez. 2011, p.113-129.

\section{Resumen}

Presenta los debates y reacciones que generaron en la Argentina los métodos difundidos en los años 1960 y 1980 conocidos como parto sin dolor, parto sin temor, parto psicoprofiláctico y parto sin violencia. Analiza las resistencias y apoyos a las primeras experiencias en el campo médico local y el papel de las mujeres en ellas. Indaga los significados de muchas de estas ideas en aquel contexto de movilización social, inestabilidad institucional, golpes militares, violencia, censura y represión, e importantes transformaciones en los roles y relaciones de género. Por último, plantea una reflexión sobre el lugar que ocupan las demandas por un embarazo y parto respetado en las políticas de sexualidad y reproducción y en el movimiento feminista.

Palabras clave: parto; historia; medicina; política; Argentina.

\section{Abstract}

The methods known as painless childbirth childbirth without fear, psychoprophylaxis, and birth without violence were popularized in the 1960s and 1980s. The article examines discussions about these methods and reactions to them in Argentina and analyzes the resistance and support encountered in the local medical field when they were first tried out, along with the role played by women. It investigates the meanings of many of these ideas within the period's context of social mobilization, institutional instability, military coups, violence, censorship, and repression but also of major transformations in gender roles and relations. Lastly, it reflects on how demands for respected pregnancy and childbirth fit in with policies on sexuality and reproduction and with the feminist movement.

Keywords: childbirth; history; Medicine; politics; Argentina. 
$\mathrm{E}$ n el contexto de profundas transformaciones sociales y culturales de la Argentina de los años sesenta, las consideraciones acerca de la maternidad, la paternidad y el modelo de familia deseable se modificaron significativamente. A pesar de la persistencia de un discurso estatal poblacionista, ayudado por el escenario de paranoia que ofrecía la 'explosión demográfica' y el sostén que le brindaba la Iglesia católica con su rechazo a la limitación de los nacimientos, el derecho de las parejas a decidir el número y el espaciamiento entre sus hijos fue ganando cada vez más apoyos (Felitti, 2009). La difusión de los modernos métodos anticonceptivos facilitó y extendió la regulación de la fecundidad, especialmente entre los sectores medios. Aunque no pueda establecerse una relación causal entre un hijo 'planificado' y un hijo querido, el hecho de que los niños formaran parte de un proyecto más consciente iba generalmente de la mano de una mayor dedicación. A su vez, el protagonismo que cobraba la infancia se apoyaba en la renovación que difundía la psicología y la importancia para el desarrollo de la personalidad que se le otorgaba a los primeros años de vida (Plotkin, 2003).

De ahí que, a pesar de los cambios en la situación social de las mujeres y su mayor presencia en el mercado de trabajo, la educación superior y la política (Feijoo, Nari, 1996), las presiones sobre la maternidad no disminuyeron sino que reconfiguraron sus formas. Como señaló Isabella Cosse (2010), la maternidad se volvió una responsabilidad más compleja, exigente y conflictiva para las mujeres, quienes tuvieron que encontrar un delicado equilibrio entre sus deseos de realización personal y el apoyo que debían a sus hijos/as. Solo en los discursos feministas, de escaso impacto social por aquel entonces, el deber maternal fue denunciado como una forma de opresión del patriarcado (Felitti, 2010a). Incluso las militantes de izquierda, quienes a comienzos de los años sesenta habían decidido posponer la maternidad para no obstaculizar sus tareas revolucionarias, pronto comenzaron a darse cuenta que el proceso de lucha iba a ser largo y necesitarían de nuevas generaciones que actuaran como retaguardia. Además, el valor que algunos/as militantes que formaban parte de una clase media educada, asignaban a las costumbres y modos de vivir del 'pueblo', hicieron de la familia numerosa un modelo a seguir. La imagen de la mujer vietnamita con un niño y un fusil en cada mano fue celebrada con lamentables y dramáticas consecuencias (Felitti, 2010b).

En estos años, ser madre se fue combinando con el trabajo, el estudio y la política, mientras el mercado de alimentos preparados, modernos artefactos domésticos, empleadas domesticas, baby sitters, guarderías y jardines de infantes crecía (Wainerman, 2005) y las revistas de crianza instaban a reflexionar sobre los roles maternos y paternos. En esta época de cambios en las relaciones de género, los varones fueron llamados a combinar su tradicional papel como referentes de autoridad con un mayor involucramiento afectivo, dando lugar a nuevos modelos de paternidad (Cosse, 2010). Fue en este escenario que las formas tradicionales de atención del embarazo y el parto comenzaron a cuestionarse. Considerar que las mujeres tenían el derecho de estar informadas sobre lo que iba a acontecer en su propio cuerpo durante la gestación y al momento de parir, respondía a estos cambios socio-culturales y al propio desarrollo de la obstetricia. Los adelantos científicos y técnicos en este campo facilitaron los diagnósticos y los tratamientos, y permitieron pensar los 
partos no solo desde sus potenciales peligros sino como un acontecimiento que podía vivirse de mejor modo, sin acatar necesariamente el mandato bíblico de 'parirás con dolor'.

En este artículo propongo analizar los debates y experiencias que generaron en la Argentina de las décadas de 1960 y 1970 las nuevas formas de atención del embarazo: el parto sin dolor, parto sin temor, parto psicoprofiláctico y parto sin violencia. En especial me interesa analizar los apoyos y resistencias que emergieron en el ámbito médico, el lugar que tuvieron las mujeres en las primeras experiencias y los significados que tomaron algunas de estas ideas en el contexto de cambios en los roles y relaciones de género, luchas anticapitalistas y creciente represión. En primer lugar, presento un breve recorrido por las principales innovaciones que se difundieron en Europa y en los Estados Unidos en estos años y su recepción en el campo médico local. A partir del análisis de publicaciones médicas, femeninas, de interés general y de divulgación científica, y de entrevistas a mujeres que formaron parte de los primeros equipos de lo que usualmente se denominó psicoprofilaxis obstétrica, analizo las relaciones de poder que estas nuevas formas de parir pusieron en cuestión. A partir de estos hallazgos, propongo colaborar con la elaboración y difusión de una historia de la sexualidad y la reproducción en la Argentina y fomentar la inclusión del embarazo y el parto respetado en la agenda política feminista, en un lugar de mayor relevancia, como parte de los derechos sexuales y reproductivos de las mujeres. ${ }^{1}$

\section{Nuevas propuestas: demandas médicas y femeninas}

Durante siglos, el embarazo y el parto fueron vividos por la mayoría de las mujeres como momentos críticos que generaban gran ansiedad y angustia dadas las altas probabilidades de no sobrevivir a ellos. Las madrastras que habitaban los cuentos campesinos y cortesanos medievales eran personajes surgidos de una dura realidad. A su vez, como prueba irrefutable de una actividad sexual previa, el embarazo y el parto fueron considerados por la tradición judeocristiana como un momento de necesario ajuste para una sexualidad femenina que había osado manifestarse (Gélis, 1991). "Multiplicaré los sufrimientos de tus embarazos; darás a luz a tus hijos con dolor. Sentirás atracción por tu marido y él te dominará" (Génesis, 3:16) fue el castigo a Eva por su desobediencia y en ella, a todas las féminas. Miedo, dolor y muerte rodeaban a este evento que fue durante mucho tiempo un acontecimiento vivido entre mujeres. Familiares, amigas y parteras eran las encargadas de acompañar y responder a las necesidades de la embarazada en su propio hogar, realizar las tareas domésticas, cuidar de sus esposos, de sus otros hijos y atender el parto.

El desplazamiento de esta red femenina por parte del poder médico y la institucionalización del parto en los hospitales han sido denunciados recurrentemente por el feminismo como otra manifestación del patriarcado en su afrenta contra la autonomía de las mujeres. No obstante, algunos estudios históricos realizados sobre estos procesos en Europa y en los Estados Unidos han permitido visibilizar a las mujeres en un rol más activo. Al promediar el siglo XIX, muchas mujeres de sectores altos y medios fueron dejando de lado el pudor y comenzaron a requerir la presencia de médicos en el momento del parto, confiando en su mayor capacidad para preservar sus vidas y también por las dificultades que fueron surgiendo para sostener la red femenina, dado el aumento de las 
migraciones, la falta de tiempo y el relajamiento en general de los lazos solidarios. En este sentido, la hospitalización pudo ser una solución para aquellas más pobres, que no contaban con recursos materiales y humanos propios para sostenerla durante ese período, y una buena opción para las más pudientes, quienes encontraban conveniente que otras personas se encargaran de ellas y de la flamante criatura (Walzer Leavitt, 1986).

Es cierto que antes de que se conocieran las ventajas de la asepsia, muchos médicos trasladaron en sus manos enfermedades mortales y los hospitales funcionaron como grandes focos infecciosos, pero una vez difundidos los descubrimientos de Louis Pasteur y la bacteriología, la mayor destreza de estos varones con los fórceps y en la administración de anestesia los hizo cada vez más solicitados. Entre 1920 y 1950, en los Estados Unidos, la demanda femenina para parir en condiciones seguras y con el menor dolor posible encontró en el método conocido como Twilight Sleep una respuesta que tuvo una rápida adhesión por parte de las mujeres, incluso entre las sufragistas. De origen alemán, este método se basaba en la combinación de morfina y escopolamina, mezcla que liberaba a la parturienta del dolor hasta llegar a provocarle amnesia. Muchas mujeres que deseaban no sentir ni recordar nada sobre sus partos se entregaron a estas prácticas, aunque dentro del propio ámbito médico se generaban grandes debates y se denunciaban sus peligros (Wertz, Wertz, 1989; Walzer Leavitt, 1986). Estas evidencias históricas invitan a repensar la visión romántica sobre los partos atendidos por parteras en un ambiente femenino y doméstico, y a reconocer el papel que tuvieron las propias mujeres en la cesión de confianza y poder a los médicos. Como sostienen estos estudios, para escapar de la muerte y del dolor cedieron tanto que luego fue difícil revertir la situación (Kholer Riessman, 1998).

Entre 1940 y 1950, a medida que la obstetricia fue salvando los peligros de salud más graves - con el uso de antibióticos para tratar las infecciones, la disponibilidad de bancos de sangre para transfusiones, los diagnósticos prenatales con rayos $\mathrm{X}$, la aplicación de oxitocina, la promoción de los cuidados prenatales y la difusión de la anestesia espinal que calmaba el dolor sin que fuera necesario perder la consciencia - las posibilidades de replantear la atención del parto fueron mayores. En este escenario, el obstetra inglés Grantley Dick Read comenzó a difundir sus teorías. De acuerdo a sus observaciones, el temor que vivían las embarazadas era resultado de la desinformación y de los mitos construidos. Para lograr un 'parto sin temor' proponía instruir a las mujeres sobre las características del proceso para superar así el síndrome del temor, tensión y de dolor provocado por el desconocimiento. Su método desarrollaba cuatro puntos básicos: educación, respiración correcta, relajamiento y ejercicios concurrentes con la respiración para llegar a un 'parto natural'. Las clases no debían ser más de diez y en ellas se debían contestar todas las preguntas relacionadas con el parto y también con la concepción; lo más importante era escuchar a las mujeres y responder a sus inquietudes en un lenguaje sencillo. Las embarazadas que asistían a su programa eran instruidas en técnicas de respiración, dietas, posturas, gimnasia y algunas nociones de crianza. La presencia del padre en el momento del nacimiento era recomendada, siempre que tuviera una preparación previa y lo mujer lo deseara (Read, 1959).

Read había desarrollado su teoría observando a los grupos de mujeres con los que trabajaba su esposa mientras vivían en Sudáfrica. Así había llegado a saber cuáles eran las 
creencias, dudas y temores más frecuentes para poder él, como especialista, brindarles una respuesta. Si bien podía parecer paradójico tener que 'aprender' sobre algo que era 'natural', Read aclaraba que había sido la cultura la que le había quitado naturalidad al alumbramiento, dotándolo de sentidos negativos y sufrientes. Para eso era la instrucción, para desaprender las falsas creencias y proyectar una imagen feliz del acontecimiento. En ese sentido consideraba al parto como un hecho normal y no como una enfermedad, un acto que producía bienestar y felicidad, una experiencia 'religiosa' que representaba el triunfo supremo de la mujer en la que el médico desempañaba un rol secundario.

Basándose en la teoría de los reflejos condicionados del fisiólogo ruso Ivan Pavlov y del método de atención del parto que se aplicaba en toda la Unión Soviética desde fines de la década de 1940, Fernand Lamaze difundió las ideas del 'parto sin dolor' en Francia y que, desde allí, se diseminaron hacia otros países. Siguiendo la escuela rusa, Lamaze explicaba que, desde pequeñas, las mujeres recibían mensajes que aseguraban que el parto era doloroso. Estas advertencias creaban una disposición mental que, una vez que éste se desencadenaba, se ponía en acción y se asimilaban todas las sensaciones con el dolor. Por eso era necesario crear una idea positiva sobre el parto y proporcionar a las mujeres un entrenamiento que les permitiera una participación activa por medio de técnicas de relajación, respiración y pujo.

En el contexto de la Guerra Fría, este método fue cuestionado no sólo por los cambios que auspiciaba en la relación médico/paciente, al dar a las mujeres un rol más dinámico y sabotear la maldición bíblica, sino que lo hacían ideológicamente sospechoso por su origen soviético. Lamaze había contado en Francia con el apoyo del Frente Popular y había aplicado por primera vez su método en la maternidad de los metalúrgicos, reforzando así las resistencias entre los más aguerridos opositores a la experiencia comunista. Como señaló Carmen Tornquist (2006), para el caso de Brasil y como veremos luego en la Argentina, las lecturas políticas sobre este 'modo soviético de parir' fueron bastante frecuentes.

Para los años 1970 cobraron importancia las ideas de Frederick Leboyer y su 'parto sin violencia'. Su método instaba a hacerse cargo del temor como un componente ineludible y otorgaba a la mujer y al bebé un protagonismo especial. Era importante generar un espacio de intimidad, un entorno de relajación, sin ruidos y con luz tenue. La posición vertical y la presencia del padre, si esta ayudaba a la relajación, eran altamente recomendadas. Leboyer había observando a las mujeres indígenas pariendo en un río y, viendo sus beneficios, también valoraba el parto en el agua. Los masajes al recién nacido eran otro elemento clave de este método que confiaba en que este tipo de nacimientos ayudaría a acabar con la violencia en el mundo (Leboyer, 2008).

En una pequeña clínica en Pithiviers, en las afueras de París, Michel Odent sostuvo la necesidad de enfrentarse con el propio cuerpo y no escapar al dolor, rechazando el suministro de drogas por sus efectos negativos sobre la madre y el bebé. En esta clínica había montado un cuarto de alumbramiento con poca luz, pintado con colores claros, piscinas de agua tibia para relajamiento y eventualmente un parto bajo el agua. La mujer elegía libremente la posición en la que iba a parir, con libertad de movimiento y expresión, y no había nursery ya que el bebé estaba siempre con su madre. La idea era mantener la atmósfera hogareña, la privacidad, aunque se estuviera en un hospital. Odent rechazaba armar un 
curso de preparación para el parto ya que consideraba que el entrenamiento terminaba por constreñir la libertad femenina (Odent, 1984).

Tanto Leboyeur como Odent, reivindicaban lo instintivo de la mujer para desarrollar su parto y el carácter prescriptivo de los entrenamientos previos, argumentando que cada embarazada debía bucear en sus propios saberes. Como advirtieron algunas feministas, si bien esta postura tenía la ventaja de sacar al médico del lugar protagónico, esto también podía redituar en una lectura esencialista de lo femenino, en la reivindicación del instinto maternal y en la invisibilidad de la construcción social que pesa sobre ese instinto. A su vez, a pesar de los enunciados que iban en sentido contrario, los médicos seguían ocupando un papel clave. En palabras de Emily Martin (2006), eran los capataces o, en el mejor de los casos, los supervisores del 'trabajo de parto'.

\section{Recepciones y resignificados en la Argentina}

A comienzos de los años 1950, Ricardo Gavensky, un médico que se había formando con Read en los Estados Unidos, comenzó a difundir la psicoprofilaxis obstétrica en la maternidad Instituto Samuel Gache del policlínico de Rawson en Buenos Aires. En 1955, publicó Parto sin temor y parto sin dolor, un libro que detallaba el método de Read y las bases de la escuela soviética - combinación expresada en el propio título - en un lenguaje que lo hacía accesible para los médicos, parteras y también para las mujeres embarazadas. ${ }^{2}$ En este texto, las ideas de Lamaze se combinaban con las disposiciones estatales de la URSS y las teorías de Read desde un objetivo común: "la educación de la embarazada para el parto sin dolor, que significa un cambio de actitud tanto físico como psíquico, bajo el influjo pedagógico y didáctico" (Gavensky, 1961, p.18).

En varias reuniones de la Sociedad de Obstetricia y Ginecología de Buenos Aires (Sogiba) se discutieron las ventajas y los obstáculos de este nuevo método. Algunos médicos consideraban beneficioso informar a las mujeres cómo se desarrollaría el parto y todo lo que involucraba la preparación anterior: tactos diagnósticos, enemas evacuantes, goteos para regularizar el ritmo contractual y la posibilidad de una episiotomía con anestesia (Rivio Martín, 1961). La validez de estas prácticas no estaba en cuestión, solo la necesidad de avisar a las mujeres lo que les iban a hacer. Una ventaja importante que algunos señalaban era que el nuevo método permitía reducir las anestesias, un recurso considerado riesgoso ya que podía obstruir el trabajo natural en el parto y provocar la necesidad de fórceps (Winograd et al., 1969). El propio Gavensky sugirió, en este ámbito científico, mejorar la organización y la capacitación del personal involucrado y por otro lado, reforzar la pedagogía que se empleaba con las asistentes a los cursos recomendando, por ejemplo, la utilización de láminas y de una pizarra para explicar 'didácticamente' el origen del dolor de parto y su relación con el temor, junto a la influencia de los relatos distorsionados, las leyendas y la tradición (Gavensky, 1964).

No todos los médicos opinaban favorablemente. Algunos se preguntaban por las ventajas de estos procedimientos, es decir, si se aplicaban con el solo objeto de aliviar el dolor de la mujer o si había otra razón de mayor peso para hacerlo (Cornelli, Magistrelli, Carbonari, 1965; Gómez et al., 1965; De la Colina, 1965). Para muchos, este era un componente que 
las mujeres debían aceptar. Además, resultaba difícil calcular el éxito de estas iniciativas por la imposibilidad de medir el dolor. La falta de personal era otro inconveniente. Para 1970, en el Policlínico Bancario, todavía no había una escuela de psicoprofilaxis. Las mujeres se preparaban con una partera y después las atendía otra, lo que algunos médicos consideraban "un disparate psicoprofiláctico en todo sentido" (Guglielmone et al., 1970, p.117).

En 1960 se creó la Sociedad Argentina de Psicoprofilaxis Obstétrica con el impulso de Gavensky y de otros médicos comprometidos con el tema. Un rasgo característico de este grupo pionero fue su cercanía con el discurso de la psicología y, en particular, del psicoanálisis, lo que otorgó un color local a la aplicación de las nuevas teorías. Para esa misma época se fundaron otros servicios de psicoprofilaxis obstétrica en el Hospital Penna, en la Maternidad Sardá y en el Hospital Alvear, este último a cargo del obstetra Ricardo Gadea. En el Hospital Metropolitano, trabajaba el equipo de Gavensky y allí se incorporó, en 1968, Hilda Schupack como psicóloga. Ella era la encargada de realizar con cada embarazada que concurría al servicio una entrevista - diseñada por ella misma - que sirviera para detectar alguna patología para el parto, la lactancia o el tipo de vínculo con el bebé y si correspondía realizar una derivación a terapia individual o a los grupos de psicoterapia que coordinaba una psiquiatra. Además, dentro del curso, dictaba una clase de psicología del embarazo, parto y puerperio (Schupack, 22 mar. 2010).

Contando con esta experiencia previa, Schupack comenzó, a mediados de la década de 1970, a trabajar con un equipo interdisciplinario de preparación para el parto formado por el obstetra Francisco Irianni, el pediatra Alberto Tripicchio Torres, la partera Eugenia Lackierowicz y la supervisión grupal del psicólogo social Marcos Berstein. Las parejas que concurrían eran de clase media universitaria o profesional, que podían costear el curso y la atención del parto en una clínica privada. La ideología que los motivaba iba más allá de un método específico: "la orientación del equipo era lograr el parto más natural posible pero sin un modelo. El parto real es el que puede tener cada paciente" (Shupack, 22 mar. 2010). También tenían la idea de que toda mujer y toda pareja que iba a tener un niño necesitaban ayuda. Es decir, no se trataba de una apuesta por las reivindicaciones feministas, ni de una cruzada contra el modelo médico hegemónico; la propuesta surgía desde la propia experiencia y la individualidad de cada madre, de cada pareja, de cada nacimiento. En estos grupos, la participación de los padres era más frecuente que en los hospitales por formar parte de esos sectores medios más influenciados por los nuevos discursos sobre la paternidad y la facilidad que ofrecía un horario de reunión nocturno, a diferencia de los cursos matutinos que ofrecían los servicios públicos.

A fines de los años 1970 este equipo realizó una experiencia similar a la que desarrollaban de forma privada en la Policlínica Central de La Matanza. La falta de tiempo era un factor de diferenciación clave; muchas mujeres iban a la consulta recién en el séptimo mes o directamente al momento de parir. Las recomendaciones de un parto vertical, de evitar la violencia que conllevaban los procedimientos innecesarios (enemas, rasurado, episiotomías de rutina) y el favorecer la participación del padre en todo momento, eran allí mucho más difíciles de llevar adelante (Irianni et al., 1980). Mirta Videla comenzó a trabajar en la atención psicológica de embarazadas en el Hospital Alvear a comienzos de los años 1970. Ella recuerda que una vez fue suspendida por una semana por mostrarle a un padre su bebé 
detrás del vidrio de la nursery, fuera del horario de visita. En esta institución estaba totalmente prohibida la presencia de varones, los cursos psicoprofilácticos eran sólo para las mujeres e, incluso, había una sala de solteras y una sala de casadas, y cursos separados para cada grupo (Videla, 3 feb. 2011).

Por otra parte, más allá de las trabas institucionales, otros factores entraban en juego. Haydee Barilari, quien trabajó como partera en la Maternidad Pedro A. Pardo a principios de los años 1950 y a partir de 1956 en la clínica privada de Eliseo Rosenvasser, recuerda que en una clase del curso en la que se mostraba una vulva a todo color, uno de los padres presentes se desmayó (Barilari, 19 jun. 2009). Para muchos varones y para muchas mujeres, la preparación para el parto ponía a su alcance información sobre temas tradicionalmente considerados tabú, como el funcionamiento del aparato reproductor femenino, el proceso de fecundación, los métodos anticonceptivos, que si bien comenzaban a tratarse también en los consultorios ginecológicos y en distintos medios de comunicación, resultaban muy movilizadores para personas educadas en el desconocimiento.

En una nota publicada en la revista Padres, Hilda Schupack y Roberto Steimberg (1973) encontraban útil la utilización del monitor ultrasónico fetal para involucrar a los padres. Los médicos, por sus conocimientos de palpación y el uso del estetoscopio obstétrico, y las madres, quienes podían sentir los movimientos a partir del segundo trimestre, tenían una relación más directa con el embarazo, pero al padre sólo le quedaba la posibilidad de colocar su mano y esperar la 'patadita'. Los autores sugerían que el monitor permitía una mayor cercanía de los varones con el hijo en camino, además de servir para ubicar la placenta, diagnosticar embarazos de gemelos y despejar dudas y ansiedades, en caso de no sentirse movimientos o tener pérdidas. Cabe decir que estas innovaciones, al tiempo que traían más 'seguridades', justificaban una mayor dependencia. En el caso del monitoreo, el cinturón limitaba los movimientos durante el trabajo de preparto y parto. Además, era frecuente interpretar como sufrimiento fetal un momento de descanso y que esto llevara a una cesárea innecesaria (Barilari, 19 jun. 2009). Por otra parte, Mirta Videla refiere a la existencia de una percepción inconsciente sobre la patología fetal por parte de las mujeres que la tecnología fue borrándoles. El precio de una mayor 'seguridad' seguía siendo caro para la autonomía femenina.

\section{Sillones y relaciones de poder}

Cerámicas precolombinas, dibujos egipcios, relatos antiguos, pinturas medievales y renacentistas muestran que, a lo largo de la historia, se utilizaron diversos modelos de sillas de parto que permitían a las mujeres mantenerse en posición vertical. De ahí que quienes argumentaron a favor de su uso en los años 1960 se presentaran a sí mismos como revitalizadores y no como creadores de esta modalidad. En la Argentina, fue Tucho Perrusi, médico clínico y biólogo, quien introdujo el primer sillón de parto vertical, luego de indagar sobre diferentes modelos históricos y realizar una investigación sobre 123 tribus indígenas que demostraban las ventajas médicas de esta posición (El invento..., 19 oct. 1965; El parto..., 1968). Sus resultados lo llevaban a señalar la paradoja de que fuera la 'mujer moderna' quien terminara usando un método tan antiguo de parir. 
En 1962, el modelo de sillón de Perrusi fue llevado a la maternidad Pedro A. Pardo. Este tenía un respaldo que daba punto de apoyo a las piernas, dos agarraderas dispuestas al extremo de cada brazo y dos pieceras que servían a la semiflexión de las piernas (Capsiski, 1976). En 1964, en un congreso de obstetricia que se realizó en Mar del Plata, Eliseo Rossenvaser se reencontró con Perruci, su antiguo vecino de La Paternal, y a partir de ese momento colaboró en la difusión del sillón (Perrusi et al., 1967) y lo llevó al Hospital Israelita, donde era jefe de servicio, y a su propia clínica privada (Barilari, 19 jun. 2009). ${ }^{3}$ Desde 1965 hasta 1974, la clínica de Rossenvaser fue una "clínica de parto vertical" (Barilari, 19 jun. 2009). Para este médico las ventajas eran evidentes: mayor comodidad, tranquilidad y adaptabilidad para la mujer que podía sentarse 'como en su casa', más fuerza para pujar, dilatación rápida, brevedad del período expulsivo, disminución del número de complicaciones y del uso de sus derivados - fórceps o cesáreas -, menor cantidad de desgarros al proteger el perineo, rápida y sencilla salida de la placenta, menor esfuerzo fetal y por consiguiente una madre y un niño más sanos y felices (Capsiski, 1976). Roberto Caldeyro Barcia, director del Centro Latinoamericano de Perinatología y Desarrollo Humano de Montevideo, y presidente de la Federación Internacional de Sociedades de Ginecología y Obstetricia, también apoyaba el uso del sillón y le daba un aval internacional.

A pesar de las anunciadas ventajas y del interés que había cobrado el tema en las revistas de crianza, para mediados de los años 1980, el sillón de partos sólo estaba disponible en unos pocos centros de la capital: la Clínica del Sol, el Mater Dei, el Sanatorio Quintana, el Finochietto, la Clínica Colegiales, la del Buen Samaritano, el Hospital Israelita, el Santoianni y el Posadas (Ditone, 1985). La falta de información y el peso que tenían los argumentos en su contra habían restringido su circulación. Para algunos detractores, que esta fuera la forma de parir de las mujeres indígenas confirmaba que se trataba de una opción 'primitiva' contrapuesta a los ideales de modernización y progreso que debía impulsar la ciencia. Otros argumentaban que el sillón ocupaba mucho lugar y restringía la movilidad en la sala. La crítica más importante eran los graves problemas que podían surgir a la hora de atender una complicación.

En 1968, en un informe periodístico que procuraba un balance de sus pros y contras, Gastón Gibelli, jefe de la Maternidad del Hospital Tornú, consideró que su única ventaja era facilitar el período expulsivo mientras que los beneficios del parto horizontal eran más significativos. En la posición acostada se podían controlar mejor los latidos fetales, era más fácil colocar las anestesias locales o paracervicales, practicar una episiotomía, realizar tactos, utilizar fórceps o realizar una cesárea sin perder tiempo, extraer la placenta de forma manual y revisar la cavidad uterina después. Ante el peligro de sufrimiento fetal y la falta de tiempo para evitar un desenlace dramático, Gibelli consideraba que el parto vertical era un peligro. Además, la variación de posiciones que se confirmaban durante la historia servía para argumentar, de manera opuesta a Perrusi, que por algo todas habían sido posteriormente descartadas (El parto..., 1968).

Rosenvasser había estudiado respuestas a muchos de estos cuestionamientos y comprobado que el sillón, en 18 segundos, se transformaba fácilmente en una camilla que permitía una cesárea (Capsiski, 1976; Barilari, 19 jun. 2009). No obstante, esto no sosegó las críticas. Al reivindicar un modo 'natural' de parir, que tomaba inspiración en el pasado y 
en las comunidades indígenas, se ponía en tensión el ideal de progreso que perseguía la ciencia médica y sus desarrollos técnicos. A su vez, eran las relaciones médico/paciente, varón/mujer las que estaban también siendo revisadas. El parto horizontal, al acostar a la mujer, la asimilaba a una enferma y la dejaba en un lugar pasivo. Bruno Elías Famá, otro partidario del parto vertical que trabajaba en el Departamento de Ginecología y Obstetricia de la Maternidad Italiana, en cambio, hacía que sus pacientes entraran caminando a la sala de partos y salieran del mismo modo, cargando ellas mismas a sus recién nacidos. De manera contraria, Carlos Pericás recomendaba un reposo de al menos diez horas y criticaba el parto vertical por falta de espacio. Por su parte, Juan León, ex jefe de las maternidades del Hospital Cosme Argerich y Bartolomé Churruca, relataba que en la Maternidad del Hospital Argerich habían propuesto a las parturientas colocarse en "cuatro patas" y no pudieron proseguir "porque las madres se resisten a adoptar una postura que les parece poco elegante". En su experiencia era la posición semi sentada y con movilidad previa de la parturienta la que daba mejores resultados (Informe..., 15 oct. 1974, p.1).

Eva Giberti, una de las principales difusoras de las 'modernas' pautas de crianza en el país, se ocupó muy especialmente de promover las ventajas del parto vertical y de analizar sus consecuencias. Ella fue una de las primeras que utilizó el sillón de Perrusi en la clínica de Rosenvasser y se hizo una férrea defensora del método. En su libro Adolescencia y educación sexual (1973), celebró ir dejando atrás viejas escenas de sumisión, como parir acostada, con las piernas en alto, atadas a las perneras, sin nada para tomarse y hacer fuerza con los glúteos expuestos y desnudos, con la sensación de estar entregada pasivamente a la actuación de médicos y parteras. Para Giberti, además de la información y de los ejercicios de relajación y respiración, resultaba crucial estar en un lugar de mayor igualdad respecto al médico y la posición sentada lo hacía posible. Por eso interpretaba las objeciones al parto vertical como una cuestión ideológica y no de espacios o tiempos (Giberti, 1983). Lo que ella opinaba se refrendaba en los testimonios de muchas mujeres atendidas de esta nueva forma. En 1965, una mujer que había parido en el sillón, contaba en el diario La Razón: "Comprobé que todos me trataron con más respeto... con más gentileza. Recuerdo que durante mis dos partos anteriores las enfermeras me impartían órdenes, me gritaban, asustaban e inhibían. Yo no podía defenderme, estaba en inferioridad de condiciones. Pero esta vez, levantaron el sillón y yo me encontraba arriba, más alta que ellos. Creo que una mujer sentada (y elevada...) inspira más respeto que una mujer acostada". Lo mismo opinaban otras mujeres también entrevistadas en el Hospital Israelita por el mismo medio de prensa (El invento..., 19 oct. 1965, p.15).

María del Carmen Brion, una feminista que en los años 1980 protagonizó una importante batalla judicial contra la práctica indiscriminada de cesáreas y el empleo de oxitocina (Brion..., 7 oct. 1990), recuerda el nacimiento de su segunda hija de este modo: "Las mujeres que parimos en lo de Rosenvasser no decíamos, como hoy suele escucharse, 'lo voy a tener con Rosenvasser'. Teníamos bien claro que éramos nosotras las que lo íbamos a tener 'en lo de Rosenvasser'" (Brion, 1995, p.37). Además, acceder a esta experiencia no era una cuestión de status, ya que la clínica trabajaba con obras sociales. Ella recuerda que en la clínica no había neonatólogo, había pediatra porque se creía que si un bebé nacía respetado, nacía sano. El curso era diferente al que se implementaba usualmente: se daban ocho 
clases que consistían en las preguntas de las mujeres y las respuestas del médico; no se enseñaba gimnasia ni técnicas de respiración. Como recuerda Brion: "Nos habíamos preparado todas para ser maratonistas o bailarinas y terminamos - todas, sin excepción pariendo colgadas como vacas listas para el sacrificio" (Brion, 1995, p.39).

Los medios de comunicación, renovados en su formato y en sus temáticas por aquellos años, colaboraron mucho en la difusión de las nuevas formas de tratar el embarazo y el parto. Las revista femenina Karina, por ejemplo, señalaba los esfuerzos que estaba haciendo la medicina para que la mujer pudiera participar "más plenamente en este acontecimiento bendito" (Ese momento..., 1966, p.59). En su columna de la revista Claudia, la periodista Adriana Civita comentaba las ventajas del método psicoprofiláctico en primera persona. Ella era ya madre de dos niños pero nunca había sido instruida sobre el parto, hasta que asistió al curso preparatorio para tener a su tercer hijo. Allí advirtió "lo injusto que había sido todo: llevarme a dar luz indefensa, asustada e ignorante como un animal al matadero" (Civita, 1960, p.11). No solo las revistas femeninas se ocupaban de esta 'novedad'. Primera Plana, una publicación que se ocupaba de temas económicos y políticos, dentro de sus secciones dedicadas a la vida moderna se explaya sobre las ventajas de las nuevas maneras de parir (El suplicio..., 1967, p.47; Puede mamá..., 1963, p.24-26; Escardó, 1963, p.28).

Barilari recuerda la gratitud de muchos matrimonios que habían tenido a sus hijos en la clínica y conserva una emotiva carta. Allí, una mujer afirmaba: "a pesar de haber sido madre de una niña hace cuatro años en un parto normal puedo asegurar que recién ahora puedo decir que hice nacer a mi hijo" (Barilari, 19 jun. 2009). Sin embargo, esa frase que revelaba un nuevo protagonismo no renegaba del poder médico. Según cuenta esta misiva, la presencia de Rosenvasser fue clave "porque el médico es la imagen de la seguridad, a él confié mi vida y la de mi hijo" (Barilari, 19 jun. 2009). Este testimonio vuelve a poner la palabra en boca de las mujeres y permite seguir reflexionando sobre ese poder que ellas fueron depositando en los médicos, en función de miedos y creencias pero también de tristes realidades. Así, la excesiva confianza colocada en la ciencia y en la técnica y el descrédito de otras prácticas consideradas primitivas fueron conformando un escenario perdurable.

\section{Parto y política en una época violenta}

En 1955, el derrocamiento de Juan Domingo Perón por parte de la autoproclamada 'revolución libertadora' (1955-1958) inauguró una nueva etapa en la historia argentina, que se caracterizó por una permanente inestabilidad política y recurrentes crisis económicas. En este clima, en 1956, Anatolio Nikolaiev fue invitado a participar de un congreso de ginecología y obstetricia que abordaría el tema de la psicoprofilaxis. En Ezeiza, no lo dejaron entrar al país. El gobierno militar consideró peligrosa esta presencia 'comunista' (Videla, 3 feb. 2011). En 1966, un nuevo golpe de estado polarizó aún más a la sociedad. La 'revolución argentina' se propuso modernizar la economía, valiéndose de medidas liberales ortodoxas, y restaurar el orden social por medio de un plan de censura y represión contra quienes cuestionaran al sistema capitalista y los 'valores occidentales y cristianos'. En 1973, la vuelta del peronismo al gobierno (1973-1976) generó grandes expectativas entre aquellos 
que vislumbraban una vía para instalar un modelo socialista, pero muy pronto esos pronósticos se derrumbaron. La represión que había comenzado en 1955 y acrecentado la 'revolución argentina' fue exacerbada en este período con el accionar de la Alianza Anticomunista Argentina (la Triple A), agrupación paramilitar que respondía a los sectores de derecha del peronismo.

En 1973, durante el brevísimo gobierno de Héctor Cámpora que precedió al regreso de Perón al país y a la presidencia, el médico pediatra Alberto Grieco asumió como secretario de Bienestar Social de la Municipalidad de San Isidro y creó el servicio de Psicología del embarazo, parto y puerperio, en la Maternidad Municipal Eva Perón de ese municipio. Por recomendación de Marie Langer y de Florencio Escardó, pediatra de gran influencia en la renovación de las pautas de crianza que antes mencioné, la psicóloga Mirta Videla se incorporó al equipo. Un grupo de 15 psicólogas y un psicólogo plantearon el diseño de una nueva forma de entender la psicoprofilaxis obstétrica, con una visión comprometida con el contexto social del lugar.

Videla había comenzado a trabajar en este tema muy joven, invitada por Mauricio Knobel a dar una clase en el curso que él dictaba en el Hospital Alvear. Al ver la necesidad de escucha que tenían las mujeres y el maltrato que diferentes personas del hospital les prodigaban, sin tener un nombramiento ni un espacio de trabajo propio, Videla se quedó allí. Según relata, al principio conversaba con las embarazadas en el baño para ganar intimidad y evitar las indiscreciones de los médicos que se preguntaban qué tenía que hacer una psicóloga en un servicio de obstetricia. A fuerza de voluntad y perseverancia, Videla se ganó un lugar hasta que, una entrevista publicada en el diario La Opinión, ya en los años 1970, donde contaba su trabajo y manifestaba sus críticas a las formas violentas en que solían atenderse los partos, motivó su despido. Ella recuerda cómo Jorge Firpo, jefe del servicio, la increpó furioso por la osadía de haber hablado con un medio sin su permiso y “con una mano sobre el teléfono, dijo: 'los psicólogos, los judíos y los comunistas son la perdición de la vida, de la patria, del hogar'. Los dos médicos que estaban al lado de él, que eran judíos, no abrieron la boca" (Videla, 3 feb. 2011).

Por eso, cuando Grieco la convocó, Videla ya estaba enterada de los efectos que podía tener su trabajo. Además, acababa de publicar un libro muy provocador en el que denunciaba el tecnicismo médico, la exaltación de la maternidad como mito y la falta de políticas de protección y promoción en el plano material. A tono con la alta politización de la época y el impacto del feminismo - aunque ella en ese momento no tuviera lecturas de este campo -, resaltaba la opresión del hombre hacia la mujer y confiaba en los cambios que podría traer una revolución social; describía los métodos anticonceptivos, considerando que esta información estaba ausente en los espacios públicos y criticaba las presiones natalistas del gobierno peronista, que no iban acompañadas de otras que protegieran la salud de la madre y el niño, ni consideraban efectivamente la creación de guarderías y jardines de infantes como sostén fundamental de las mujeres trabajadoras. Maternidad: mito y realidad no solo denunciaba los maltratos hospitalarios que padecían las mujeres, sino el sistema social y de género que los avalaba (Videla, 1974).

En 1974, Leboyer fue invitado a Buenos Aires para promocionar su método de 'parto sin violencia', justamente en un momento político y social de extrema violencia que serviría 
de antesala para la sangrienta dictadura que estaba a punto de instalarse en el país. En una reunión entre colegas, Videla tuvo la oportunidad de cuestionar la viabilidad de este método en los hospitales de la Argentina que estaban "muy lejos de su clínica parisina con alfombra blanca y flautista hindú en la sala de partos" (Videla, 2003). En un programa televisivo, al que Leboyer había sido invitado, Videla volvió a insistir en la situación hospitalaria argentina, en donde "los gatos se comen la placenta porque no hay un balde para tirarla". A tono con el clima de época del momento y una misoginia mucho más antigua, Leboyer le respondió: "típica mujer sudamericana, muy hermosa y politizada" (Videla, 3 feb. 2011). La reacción de Videla ante este intento de cosificación fue dura y, como puede suponerse, censurada.

El trabajo de Videla, y el de otras personas que cuestionaban el modelo médico hegemónico y sus relaciones de poder, fue visto como una amenaza por la dictadura militar que usurpó el gobierno el 24 de marzo de 1976. El servicio de la maternidad de San Isidro fue cerrado por 'decreto de seguridad nacional'. El argumento informal para sostener esa decisión fue, según el coronel médico que intervino la institución, que no valía la pena 'darles margaritas a los chanchos', esto es, trabajar con las mujeres embarazadas de sectores populares para mejorar sus condiciones de bienestar y respetar sus derechos. Videla recuerda el impacto del trabajo social que realizaban: "Estábamos en las villas, en las unidades básicas, íbamos a buscar a menores que no venían porque tenían miedo que la policía las denunciara, hicimos una modificación de toda la asistencia, pusimos sanciones a quienes maltrataban a las mujeres, introdujimos anestesistas porque no había, compramos una ambulancia, no estaban los recursos mínimos" (Videla, 3 feb. 2011).

En esta época, la Sociedad Argentina de Psicoprofilaxis Obstétrica fue también disuelta. Alberto Hakin, quien era presidente de la entidad, convocó a sus integrantes a una reunión en su casa y allí les comunicó su inminente nombramiento como funcionario del gobierno de facto y les dijo: "Dado lo que venimos trabajando, y nuestra manera de pensar, algunas cosas yo comparto" y dice, específicamente, "menos con Mirta que es la guerrillera de la obstetricia". "Quedan dos opciones: o desaparecemos la sociedad y quemamos las actas, y hacen de cuenta que no me han conocido, o todos ustedes van a investigación al Side (Secretaría de Inteligencia de Estado)" (Videla, 3 feb. 2011). La decisión fue 'desaparecer' la Sociedad y continuar trabajando de forma individual o grupal pero sin tanta visibilidad, con mucho miedo pero con el mismo compromiso. Fue recién con la recuperación de la democracia que los trabajos en las 'catacumbas' de la dictadura volvieron a hacerse visibles y comenzaron, muy lentamente, a posicionarse como una cuestión de derechos humanos.

\section{Consideraciones finales}

Los cambios que se dieron a partir de los años 1950 en la atención del parto se inscribieron en un contexto de transformaciones sociales y culturales amplias que afectaron los roles y relaciones de género y los modelos familiares. A la vez respondieron a un renovado interés médico por mejorar la atención y minimizar sus complicaciones, aprovechando la difusión de nuevos conocimientos y herramientas tecnológicas que habían vuelto al parto menos peligroso. El parto sin dolor, parto sin temor, parto psicoprofiláctico, parto vertical, parto 
sin violencia, fueron diferentes modos de denominar y pensar la atención obstétrica que pusieron en evidencia diferentes concepciones sobre la relación médico/paciente y entre varones y mujeres. Todos ellos tuvieron en común el considerar a las mujeres en un rol más activo, ya no como 'enfermas' sino como sujetos capaces de protagonizar la experiencia. En algunos casos, los padres fueron también interpelados y llamados a ocupar un lugar más comprometido y cercano en el nacimiento de sus hijos.

En la Argentina, estas transformaciones se relacionaron con el fuerte impacto que tenía la difusión del psicoanálisis y el contexto social y político que atravesaba el país. Los equipos de psicoprofilaxis obstétrica que trabajaban en los hospitales públicos estaban promoviendo el derecho de la mujer a ser tratada con respeto y a parir en condiciones dignas y con mayor autonomía. Esta visión participativa, y mucho menos jerárquica, implicaba una concepción distinta del cuidado de la salud, de la maternidad y de las mujeres que cuestionaba el modelo médico tradicional y que, incluso, daba un lugar significativo a la psicología y sus principales representantes, también mujeres. Lo que estaba en juego era algo más profundo que la superación del dolor de parto. Por eso, que las mujeres dejaran de estar acostadas y que pudieran ubicarse al mismo nivel del médico motivó tantas resistencias.

Por otra parte, las vinculaciones que se establecían entre las nuevas formas de atención al parto y el comunismo, si bien pudieron tener un origen en las influencias de la escuela soviética, plasmaron una situación mucho más cercana y concreta. El cuestionamiento al maltrato que ejercían muchos médicos sobre las mujeres, especialmente sobre las de menores recursos, se conjugaba con un trabajo social que las dictaduras militares consideraron subversivo. Durante el proceso de reorganización nacional, los servicios de psicoprofilaxis obstétrica se cerraron porque no tenía sentido 'darles margaritas a los chanchos'. Promover un parto sin violencia en el contexto del terrorismo de estado resultaba una paradoja que llegó a su máximo absurdo cuando se supo de las condiciones infrahumanas en las que parían las detenidas desaparecidas en los centros clandestinos de detención de la dictadura, cuyo destino final fue la muerte y la apropiación ilegal de sus hijos. ${ }^{4}$

Este artículo propuso visibilizar esta parte de la historia de los derechos sexuales y reproductivos en la Argentina, considerando que el parto es un evento crucial en la vida de muchas mujeres. Es cierto que esta reivindicación puede ser apropiada por actores que estratégicamente se apoyan en construcciones esencialistas sobre la maternidad, elaboraciones que tanto le ha costado desmontar al feminismo y a los estudios de género. No obstante, y a pesar del peligro de dar argumentos a los grupos 'anti derechos reproductivos' ${ }^{5}$, considero necesario seguir trabajando para que los derechos del embarazo y el parto sean incluidos en un lugar destacado de la agenda política del feminismo. Desde el 2004, Argentina cuenta con una ley de parto humanizado (ley 25.929) que reconoce los derechos de padres e hijos durante el proceso de nacimiento. ${ }^{6}$ Sin embargo, su aplicación sigue siendo reducida, los maltratos hospitalarios persisten y solo queda recurrir a los servicios privados, de alto costo monetario, para vivir un embarazo y un parto de acuerdo a las pautas que cada mujer y/o pareja elija.

Pese a las denuncias y a las campañas internacionales sobre este tema, se percibe que para una parte del feminismo local ocuparse de esta cuestión podría dar un mensaje ambiguo 
en relación a la lucha actual, y desde ya clave, por la despenalización y legalización del aborto. De hecho, la reciente extensión de la asignación universal por hijo a las mujeres que comienzan la semana 12 de gestación ha provocado importantes discusiones por sus implicancias en el debate sobre este tema. Sin desconocer este escenario, luchar por un embarazo y parto respetado es reivindicar la autonomía corporal femenina, la capacidad de decidir y de sentir de las mujeres y transformar lo personal en político. Pensar estos momentos como parte de la vida sexual de muchas mujeres y no solo de sus funciones reproductivas, no resulta fácil. ${ }^{7}$ La maternidad ha sido vivida y definida como obligación y en muchos casos sigue siéndolo. Apostar a defender los derechos que ella implica cuando es libremente elegida se presenta como un desafío, difícil pero también imprescindible.

\section{NOTAS}

${ }^{1}$ Sin desconocer que en muchos casos los embarazos no son el resultado de una libre elección sino consecuencia de situaciones de violencia de género y/o falta de acceso a la educación sexual, a los medios anticonceptivos y al aborto, en este artículo se pone el acento en los derechos que hacen al embarazo y el parto, en todos los casos y en especial, cuando la maternidad ha sido libremente elegida. En esta misma línea, pueden consultarse los trabajos reunidos en Felitti, 2011.

${ }^{2}$ De hecho, el ejemplar del libro que analizo fue comprado en 1965 por una embarazada.

${ }^{3}$ Rosenvasser fue miembro fundador de la Asociación Argentina de Protección Familiar (AAPF) y trabajaba junto con el pastor protestante Luis Parrilla en un centro de atención comunitaria en La Paternal (Felitti, 2009). Su compromiso con la planificación familiar venía dado, como sucedía con otros colegas de la AAPF, por la lucha contra el aborto.

${ }^{4}$ En 1997, Mirta Videla dedicó a estas mujeres la reedición de Maternidad: mito y realidad.

${ }^{5}$ Elijo esta forma para denominar a aquellos grupos que están en contra de la anticoncepción, la educación sexual y la despenalización y legalización del aborto. Considero que otorgarles el estatuto de ser 'pro vida' los favorece ante la opinión pública y hace invisible el hecho de que el movimiento feminista está también a favor de la vida, la dignidad y la libertad de las mujeres.

${ }^{6}$ En esta normativa se establece el derecho de la mujer a ser tratada con respeto, de modo personalizado, garantizándole su intimidad; ser considerada como una persona sana, de modo que sea protagonista de su propio parto. El parto natural se define como aquel que respeta los tiempos biológicos y psicológicos, evitando prácticas invasivas. La mujer debe ser informada sobre la evolución de su parto, el estado de su hijo o hija; no ser sometida a ningún examen o intervención cuyo propósito sea de investigación, salvo consentimiento por escrito; estar acompañada por una persona de su confianza y elección; tener a su lado a su hijo o hija durante la permanencia en el establecimiento sanitario; ser informada, desde el embarazo de los beneficios de la lactancia materna y recibir apoyo para amamantar.

${ }^{7}$ Vale este ejemplo sobre las posibilidades de vincular la sexualidad, el placer y las relaciones amorosas al proceso. Ricardo Gadea, en lugar de usar eutocol para estimular las contracciones uterinas, recomendaba la succión mamaria como método de inducción más natural del parto. Mirta Videla recuerda las resistencias de sus colegas y que algunos lo consideraban por esto un 'degenerado'. No obstante, mientras Gadea recomendaba que se hiciera con un sacaleche, Videla iba más allá y les decía a las mujeres que lo hicieran con la succión de su propia pareja (Videla, 3 feb. 2011).

\section{REFERENCIAS}

BARILARI, Haydee.

Depoimento. Entrevistadora: Karina Felitti. Buenos Aires. Grabación digital (2:30h). 19 jun. 2009.

BRION...

Brion: el fallo es un paso importante. Crónica, Buenos Aires, año 24, n.9141. 7 oct. 1990.
BRION, María del Carmen.

El parto de la hembra humana. Buenos Aires: Biblos. 1995.

CAPSISKI, Jorge.

Parto vertical. Vivir, Buenos Aires, año 1, n.6, p.64-68. 1976. 
CIVITA, Adriana.

Pro y contra. Claudia, Buenos Aires, año 4, n.37, p.11. 1960 .

CORNELLI, Osvaldo; MAGISTRELLI, Hugo; CARBONARI, Alfredo.

Experiencia acerca de la anestesia paracervical en el parto. Revista de la Sociedad de Obstetricia y Ginecología de Buenos Aires, Buenos Aires, v.19, n.619, p.177-180. 1965.

COSSE, Isabella.

Pareja, sexualidad y familia en los años sesenta. Buenos Aires: Siglo XXI. 2010.

\section{DE LA COLINA.}

Discusión. Revista de la Sociedad de Obstetricia y Ginecología de Buenos Aires, Buenos Aires, v.18, n.614, p.108. 1965

DITONE, Susana.

La silla de parto. Vivir/Buenos Aires, s.n., año 10, p.25-29. mayo 1985.

\section{EL INVENTO...}

El invento más antiguo del mundo. La Razón, Buenos Aires. Suplemento Siete Días, p.14-15. 19 oct. 1965.

EL PARTO...

¿El parto vertical o el parto horizontal? Mamina, Buenos Aires, p.80-85. dic. 1968.

EL SUPLICIO...

El suplicio de la dulce espera. Primera Plana, Buenos Aires, n.250, p.47. 1967.

ESCARDÓ, Florencio.

El trabajo de ser mamá: de la maldición bíblica al parto con verdadero amor. Primera Plana, Buenos Aires, año 2, n.16, p.28. 1963.

ESE MOMENTO...

Ese momento que solo una mujer puede vivir. Karina, Buenos Aires, n.2, p.59. jun. 1966.

FEIJOO, María del Carmen; NARI, Marcela. Women in Argentina during the 1960's. Latin American Perspectives, Riverside v.23, n.1, p.7-26. 1996.

FELITTI, Karina (Coord.).

Madre no hay una sola: experiencias de maternidad en la Argentina. Buenos Aires: Ciccus. 2011.

FELITTI, Karina.

Sexualidad y reproducción en la agenda feminista de la segunda ola en la Argentina (1970-1986). Estudios Sociológicos, México, v.28, n.84, p.791-812. 2010a.

FELITTI, Karina.

Poner el cuerpo: género y sexualidad en la política revolucionaria de Argentina en la década de 1970. In: Bloch, Avital H. (Ed.).
Political and social movements during the sixties and seventies in the Americas and Europe. México: Universidad de Colima. p.69-93. 2010b.

\section{FELITTI, Karina.}

Regulación de la natalidad en la historia argentina reciente: discursos y experiencias (1960-1987). Tesis (Doctorado) - Facultad de Filosofía y Letras, Universidad de Buenos Aires, Buenos Aires. 2009.

FUNDACIÓN PALABRA DE VIDA. El libro del Pueblo de Dios: la Biblia. Trad. Armando J. Levoratti, Alfredo B. Trusso Buenos Aires: Editorial San Pablo. 2002.

GAVENSKY, Ricardo V.

Método continuo para la enseñanza de la psicoprofilaxis del parto. Revista de la Sociedad de Obstetricia y Ginecología de Buenos Aires, Buenos Aires, v.43, n.607, p.115-125. 1964.

GAVENSKY, Ricardo V.

Parto sin temor y parto sin dolor: educación de la embarazada para el parto sin dolor. Buenos Aires: El Ateneo. 1.ed., 1955. 1961.

GÉLIS, Jacques.

History of childbirth: fertility, pregnancy and birth in early modern Europe. Boston:

Northeastern Press. 1991.

GIBERTI, Eva.

El parto vertical. Uno mismo, Buenos Aires, año 1, n.6. p.38-42. 1983.

GIBERTI, Eva.

Adolescencia y educación sexual. Buenos Aires: Editores Roberto O. Antonio. t.1. 1.ed., 1969. 1973.

GÓMEZ, Daniel et al.

La analgesia paracervical en el parto normal. Revista de la Sociedad de Obstetricia y Ginecología de Buenos Aires, Buenos Aires, v.19, n.614, p.106-108. 1965.

GUGLIELMONE, Pedro Luis et al.

Conducta obstétrica en la primípara añosa. Revista de la Sociedad de Obstetricia y Ginecología de Buenos Aires, Buenos Aires, v.24, p.115-120. 1970.

\section{INFORME.}

Informe sobre el parto. Tonus, Buenos Aires, año 3, n.64, p.1. 15 oct. 1974.

IRIANNI, Francisco et al.

Salud materno infantil: propuesta de prevención durante el embarazo, parto y puerperio. Boletín de la Oficina Sanitaria Panamericana, Washington, v.89, n.3, p.217-227. 1980 . 
KHOLER RIESSMAN, Catherine.

Women and medicalization: a new perspective. In: Weitz, Rose (Ed.). The politics of women's bodies: sexuality, appearance and behavior. Oxford: Oxford University Press. p.46-63. 1998.

LEBOYER, Frederick.

Por un nacimiento sin violencia. Madrid:

Mandala. 1.ed., 1976. 2008.

MARTIN, Emily.

A mulher no corpo: uma análise cultural da reprodução. Rio de Janeiro: Garamond. 2006.

ODENT, Michel.

El nacimiento renacido. Buenos Aires: Errepar. 1984

PERRUSI, Tucho et al.

Parto vertical. Trabajo presentado en el 12.

Congreso Argentino de Obstetricia y

Ginecología, 23-27 oct. 1967. Buenos Aires. 1967.

PLOTKIN, Mariano.

Freud en las pampas: orígenes y desarrollo de una cultura psicoanalítica en la Argentina (1910-1983). Buenos Aires: Sudamericana. 2003.

PUEDE MAMÁ....

¿Puede mamá conservarse siempre linda?. Primera Plana, Buenos Aires, n.217, p.24-26. 1963.

READ, Grantly Dick.

Educación para el parto sin dolor. Buenos Aires: Editorial Central. 1959.

RIVIO MARTÍN, Juan.

El parto psicoprofiláctico conducido. Revista de la Sociedad de Obstetricia y Ginecología de Buenos Aires, Buenos Aires, n.558, p.220-227. 1961.

SCHUPACK, Hilda.

Depoimento. Entrevistadora: Karina Felitti. Buenos Aires. Grabación digital (3:25h). 22 mar. 2010.

SCHUPACK, Hilda; STEIMBERG, Roberto. Los latidos del bebé. Padres, Buenos Aires, n.6, p.94-98. 1973.
VIDELA, Mirta.

Depoimento. Entrevistadora: Karina Felitti. Buenos Aires. Grabación digital (2:15h). 3 feb. 2011.

TORNQUIST, Carmen.

El parto sin dolor en la América del Sur. In: Congreso Iberoamericano de Estudios de Género, 3., Jornadas Nacionales de Historia de las Mujeres, 8., 25-28 oct. 2006, Córdoba. Actas... Córdoba: Universidad Nacional de Córdoba. CD-Rom. 2006.

VIDELA, Mirta.

Preñeces, pujos y alumbramientos. Conferencia inicial de las 1 as Jornadas Interdisciplinarias sobre Parto y Nacimiento, 24-25 nov. 2003, Buenos Aires. Buenos Aires: Asociación de Psicólogos de Buenos Aires. Disponible en: http://www.maternidadmitoyreal.com.ar/ 2009Acesso em:/01/16/interdisciplina-prenecespujos-y-alumbramientos/. Acceso en: 25 abr. 2011. 2003.

VIDELA, Mirta.

Maternidad: mito y realidad. Buenos Aires: A. Peña Lillo. 1974.

WAINERMAN, Catalina.

La vida cotidiana en las nuevas familias: ¿una revolución estancada? Buenos Aires: Lumiere. 2005.

WALZER LEAVITT, Judith.

Brought to bed: childbearing in America (1750-1950). Oxford: Oxford University Press. 1986.

WERTZ, Richard; WERTZ, Dorothy. Lying-in: a history of childbirth in America. London: Yale University Press. 1989.

WINOGRAD, Raúl Héctor et al. Diazepam en el trabajo de parto. Revista de la Sociedad de Obstetricia y Ginecología de Buenos Aires, Buenos Aires, n.677, p.410-415. 1969.

ZIMMERMAN, Héctor.

La revolución de los niños. Karina, Buenos Aires, n.6, p.91-93, 123. 1966. 